\title{
RESEARCH
}

Open Access

\section{The impact of sociodemographic factors on the utilization of radiation therapy in breast cancer patients in Estonia: a register-based study}

Fereshteh Shahrabi Farahani ${ }^{1}$, Keiu Paapsi ${ }^{2}$ and Kaire Innos ${ }^{2^{*}}$ (1)

\begin{abstract}
Background: Radiation therapy is an important part of multimodal breast cancer treatment. The aim was to examine the impact of sociodemographic factors on radiation therapy use in breast cancer (BC) patients in Estonia, linking cancer registry data to administrative databases.

Methods: Estonian Cancer Registry provided data on women diagnosed with BC in Estonia in 2007-2018, including TNM stage at diagnosis. Use of radiation therapy within 12 months of diagnosis was determined from Estonian Health Insurance Funds claims, and sociodemographic characteristics from population registry. Receipt of radiation therapy was evaluated over time and by clinical and sociodemographic factors. Poisson regression with robust variance was used to calculate univariate and multivariate prevalence rate ratios (PRR) with $95 \%$ confidence intervals $(\mathrm{Cl})$ for receipt of radiation therapy among stage I-III BC patients age $<70$ years who underwent primary surgery.

Results: Overall, of 8637 women included in the study, 4310 (50\%) received radiation therapy within 12 months of diagnosis. This proportion increased from 39 to $58 \%$ from 2007 to 2009 to 2016-2018 $(p<0.001)$. Multivariate regression analysis showed that compared to women with stage I BC, those with more advanced stage were less likely to receive radiation therapy. Receipt of radiation therapy increased significantly over time and was nearly $40 \%$ higher in 2016-2018 than in 2007-2009. Use of radiation therapy was significantly lower for women with the lowest level of education compared to those with a university degree (PRR 0.88, $95 \% \mathrm{Cl} 0.80-0.97$ ), and for divorced/widowed women (PRR 0.95, $95 \% \mathrm{Cl} \mathrm{0.91-0.99)} \mathrm{and} \mathrm{single} \mathrm{women} \mathrm{(PRR} \mathrm{0.92,} 95 \% \mathrm{Cl}$ 0.86-0.99), compared to married women. Age at diagnosis, nationality and place of residence were not associated with receipt of radiation therapy.
\end{abstract}

\footnotetext{
* Correspondence: kaire.innos@tai.ee

${ }^{2}$ Department of Epidemiology and Biostatistics, National Institute for Health Development, Hiiu 42, 11619 Tallinn, Estonia

Full list of author information is available at the end of the article
}

C C The Author(s). 2021 Open Access This article is licensed under a Creative Commons Attribution 4.0 International License, which permits use, sharing, adaptation, distribution and reproduction in any medium or format, as long as you give appropriate credit to the original author(s) and the source, provide a link to the Creative Commons licence, and indicate if changes were made. The images or other third party material in this article are included in the article's Creative Commons licence, unless indicated otherwise in a credit line to the material. If material is not included in the article's Creative Commons licence and your intended use is not permitted by statutory regulation or exceeds the permitted use, you will need to obtain permission directly from the copyright holder. To view a copy of this licence, visit http://creativecommons.org/licenses/by/4.0/ The Creative Commons Public Domain Dedication waiver (http://creativecommons.org/publicdomain/zero/1.0/) applies to the data made available in this article, unless otherwise stated in a credit line to the data. 
Conclusions: The study showed considerable increase in the use of radiation therapy in Estonia over the study period, which is in line with increases in available equipment. The lack of geographic variations suggests equal access to therapy for patients living in remote regions. However, educational level and marital status were significantly associated with receipt of radiation therapy, highlighting the importance of psychosocial support in ensuring equal access to care.

Keywords: Breast cancer, Radiation therapy, Stage, Social determinants, Education, Marital status, Estonia

\section{Background}

Breast cancer $(\mathrm{BC})$ is a major health burden among women worldwide as well as in Estonia. Although overall $\mathrm{BC}$ incidence has increased in Estonia [1], mortality from BC has decreased steadily since 2000 [2]. However, there's still a survival gap between Estonia and more developed countries [3], despite rapid increase observed since 1990s, particularly for locally/regionally spread cancers [4]. BC five-year relative survival ratio in Estonia was $81 \%$ in 2012-2016 [5], whereas the survival of BC patients in the Nordic countries and England was approximately 90 and $85 \%$, respectively, for the same period [6, 7].

The most likely reason for inferior survival is late diagnosis, as the proportion of $\mathrm{BC}$ cases diagnosed at early stage is lower in Estonia than in many other European countries [8]. However, the role of treatment should be considered as well.

Radiation therapy (RT) is an essential part of multimodal $\mathrm{BC}$ treatment. In early $\mathrm{BC}, \mathrm{RT}$ is the standard of care after breast-conserving surgery (BCS) and is sometimes also indicated after mastectomy [9]. RT helps to decrease the risk of local recurrence or death in $\mathrm{BC}$ patients after BCS [10-12]. Patients with locally advanced disease may receive $\mathrm{RT}$ in combination with surgery and systemic therapy, and those with metastatic disease, to relieve symptoms and improve quality of life [13].

The number of RT equipment in Estonia was one of the lowest in Europe in 2012, with 3.0 megavoltage (MV) units per million population compared to the median of 5.3 of 28 European countries [14]. RT in Estonia is done at two specialist cancer centres, located in Tallinn (the capital of Estonia) and in Tartu (a university town in Southern Estonia). During 2007-2011, three MV units were in use; one was added in 2011, and two more in 2016, which currently totals 4.6 MV units per million population $[14,15]$.

Estonia has a population of 1.3 million, two-thirds of which are ethnic Estonians and one-fourth are Russians. After regaining independence in 1991 and the stabilization of the political situation, fundamental health care reforms took place, including mandatory health insurance and restructured hospital network. More recent adjustments have been marginal, aiming to harmonize the framework with EU legislation. Health insurance tax is paid by employers for their employees, and by the state for other categories of insured people (e.g., children, retired and unemployed persons, pregnant women). Health insurance covers a broad range of curative and preventive services, including standard cancer care, based on contractual relations between Estonian Health Insurance Fund (EHIF) and service providers. In general, $95 \%$ of the population is covered by health insurance [16].

Nevertheless, disparities in overall health status, cancer mortality, as well as BC early detection have been reported by educational level, nationality, or region of residence [17-20]. In particular, the North-Eastern industrial region bordering Russia has been previously recognized as problematic in terms of health [20]. The islands of Western Estonia and the North-Eastern region can be considered the most remote from cancer centres.

Internationally, social and geographic variations in receipt of BC treatments, including RT, have been widely documented in different settings and populations, revealing the unfavourable impact of geographic distance from services as well as barriers related to race/ethnicity or educational level [21-32].

The use of RT in women with BC in Estonia has previously been studied only within the framework of international high-resolution studies, demonstrating a drastic increase in the use of BCS + RT in early BC from $9 \%$ to 1997 to $75 \%$ in 2011 [8, 33]. Nevertheless, among nine European countries, the use of BCS + RT in Estonia was the second lowest [8]. There have been no studies examining receipt of RT in relation to individual sociodemographic factors in Estonia.

This study was designed within the framework of social determinants of cancer examining social gradients on health-care delivery level, trying to shed light on the effect of social and behavioural/psychological factors on access to and use of health services, linking data available from different registration systems [34].

Cancer cases were identified from the Estonian Cancer Registry (ECR), a population-based registry with nationwide coverage, which has reliable cancer incidence data from 1968 [5]. It is compulsory for all physicians and pathologists working in Estonia to report cancer cases to ECR. Additionally, ECR uses multiple sources to ascertain cancer cases including regular linkages with two 
cancer centres and trace-back of cases identified via death certificates. The completeness of case reporting is high as evidenced by data quality indicators [5]. Registry data on surgical treatment is considered rather reliable [35], but the completeness of RT data has not been evaluated. Failure of cancer registries to capture complete and accurate information on nonsurgical cancer treatment has been reported elsewhere [36, 37].

Therefore, RT data were collected from the central electronic database of EHIF which is a reimbursement database containing claims for all medical procedures performed in insured persons. Sociodemographic data were obtained from the population registry, a national database maintained and developed by Estonian government containing main personal information on all Estonian citizens and residents.

The aim of the study was to examine the utilization of RT among BC patients in Estonia over time, by sociodemographic factors and stage at diagnosis, combining data from the cancer registry and other populationbased databases. An additional aim was to assess the completeness of RT data at the ECR.

\section{Materials and methods}

\section{Data collection and definitions}

Information on BC cases diagnosed in 2007-2018 was retrieved from the ECR. ECR uses the 3rd edition of International Classification of Diseases for Oncology (ICD-O-3) for coding topography and morphology of the tumours. ECR provided data on all invasive $\mathrm{BC}$ cases (ICD-O-3 topography codes C50.0-C50.9) diagnosed in Estonia between 2007 and 2018, regardless of cancer sequence $(n=8804)$. Data were collected using the same notification form during the study period. Male patients $(n=68)$, those with stage 0 disease $(n=10)$, death certificate only cases $(n=69)$, and autopsy cases $(n=20)$ were excluded from the analysis. The data obtained from the ECR included personal data, and data on diagnosis (date of diagnosis, age, and stage at diagnosis) and treatment (surgery and RT). Age at diagnosis was collapsed into four categories: $<50,50-59,60-69, \geq 70$ years. Stage at diagnosis was categorized according to the Union for International Cancer Control TNM classification version 7. Period of diagnosis was divided into four three-year categories to account for the changes in the availability of RT equipment: 2007-2009, 2010-2012, 2013-2015 and 2016-2018. Region of residence was collapsed into five categories: Northern, Western, Central, NorthEastern and Southern Estonia. RT and surgery data included dates of treatment and description of procedures in text format.

Additional data on treatment was retrieved from the EHIF database which contains claims for all medical procedures performed in insured persons including dates of services and diagnostic codes according to International Statistical Classification of Diseases and Health Problems 10th Revision (ICD-10).

For BC cases included in the study, EHIF provided data on claims for RT (separately for RT planning and procedures), chemotherapy, and surgery for 2007-2019. The primary outcome was defined as receipt of RT, based on claims filed for at least one RT procedure performed within 12 months of diagnosis. The time frame was set to account for radiation performed during initial course of therapy. Time between diagnosis and RT was calculated from the date of cancer diagnosis to the date of starting RT. RT was considered as not received for cases for whom EHIF database included claims only for RT planning.

All patients with surgery reported within 12 months of diagnosis were considered as having had primary surgery. Type of surgery was categorised into BCS or mastectomy/other based on either procedure codes on insurance claims or description of surgery at ECR.

Data on sociodemographic variables for BC cases included in the study were obtained from the population registry. Nationality was grouped into Estonian, other nationalities, and unknown. Educational level was categorised as university and higher education, secondary studies plus vocational education, secondary studies, basic or primary studies and unknown. Marital status was classified as married, divorced/widowed, single, and unknown.

Data linkages were done using unique personal identification numbers, which have been in use in Estonia since 1992.

\section{RT data validation}

The validity of EHIF RT data was checked against an existing high-resolution database collected for a previous study including diagnosis and treatment data for BC cases diagnosed in 2011 from the medical records of cancer centres and other hospitals [15].

As an additional analysis, we evaluated the completeness of RT data at the ECR, comparing RT data reported to the ECR on cancer notification form to RT data obtained from EHIF.

\section{Statistical analysis}

Statistical analysis was performed with statistical software Stata 16 [38]. Chi-square test was used to compare proportions between groups. Two-sided $p$-value $<0.05$ was considered statistically significant. The prevalence rate ratio (PRR) for receipt of RT with $95 \%$ confidence intervals $(\mathrm{CI})$ was calculated using univariate and multivariate Poisson regression models with robust variance, performed with generalized linear models with Poisson family and log link function in Stata. This method was 
selected because the odds ratio calculated with logistic regression tends to overestimate the association between variables when the prevalence is moderate to high [39]. In regression modelling, we included women with stage I-III cancer, age $<70$ at diagnosis who underwent primary surgery, to account for treatment guidelines. Cases with 'unknown' educational level, marital status or nationality were also excluded from modelling. A sensitivity analysis was conducted with BCS + RT as an outcome variable among women with stage I-II cancer.

\section{Ethics}

The study protocol was approved by the Tallinn Medical Research Ethics Committee.

\section{Results}

\section{Patient characteristics}

In total, 8637 women met the inclusion criteria for this study; the proportion of cases with microscopic verification was $97 \%$ (Table 1). Overall, $49.9 \%$ of the patients received RT. Receipt of RT increased considerably over time from $39.1 \%$ in $2007-2009$ to $57.9 \%$ in $2016-2018$ ), was highest in age group $50-59(65.1 \%, p<0.001)$ and at stage I $(66.1 \%, p<0.001)$. There was no difference in RT use by nationality. RT utilization was the highest in Southern Estonia (53.9\%) and the lowest in Western Estonia $(45.3 \%, p<0.001)$. RT was used in $58.0 \%$ of women with higher than secondary education compared to $28.8 \%$ among women who had completed basic and primary studies $(p<0.001)$. The proportion of married women who received RT was $59.9 \%$, which was higher in comparison to single (50.0\%) and divorced/widowed women $(43.2 \%, p<0.001$ for both). Patients who received primary surgical treatment or chemotherapy, were more likely to receive RT than those who did not receive these treatments $(p<0.001$ for both).

Among women with stage I-III cancer aged $<70$ years at diagnosis who underwent primary surgery, a significant increase in RT use was seen from $56.9 \%$ in $2007-$ 2009 to $78.3 \%$ in $2016-2018$ (Table 2). Significant increases over the study period were observed in all subgroups. The largest increase by stage was seen for stage III, from 54.6 to $86.1 \%$. RT utilization increased for all age groups, but the most among women aged 60-69, from 51.2 to $78.7 \%$. Among women with basic and primary educational level, receipt of RT showed a significant upward trend from 42.4 to $73.3 \%$; among divorced/ widowed women, from 54.1 to $77.4 \%$.

\section{Regression analysis}

Table 3 presents the results of regression modelling for women with stage I-III cancer aged $<70$ years at diagnosis who underwent primary surgery $(n=4312)$. In univariate analysis, receipt of RT was associated with period of diagnosis, age, stage, educational level, and marital status. After adjusting for other variables in multivariate analysis, a nearly $40 \%$ increase in receipt of RT was observed over the study period (PRR 1.37, $95 \%$ CI 1.29-1.45). Age showed a slight reverse U-shape association with RT use, which was borderline significant. RT use varied by stage, with stage I patients having the highest rates and stage II patients the lowest (PRR 0.79, $95 \%$ CI 0.75-0.82). Women with the lowest level of education were significantly less likely to receive RT than other educational categories (PRR 0.88, $95 \%$ CI 0.80 0.97). Also, compared to married women, lower rates of RT utilization were observed for divorced/widowed women (PRR 0.95, $95 \%$ CI 0.91-0.99) and for single women (PRR 0.92, $95 \%$ CI 0.86-0.99). No associations were observed in multivariate analysis across regions of residence or by nationality.

In sensitivity analysis including only women with stage I-II cancer aged $<70$ years at diagnosis who underwent primary surgery $(n=3485)$ and using $\mathrm{BCS}+\mathrm{RT}$ as outcome variable, the PRRs remained similar, but confidence intervals widened.

\section{RT data validation}

The primary outcome variable, receipt of RT within 12 months of diagnosis, identified from insurance claims, was validated against data collected for a previous highresolution study. There was a $99.4 \%$ agreement as two cases who were reported to have undergone RT according to medical records had no claims in the EHIF database.

Evaluation of the completeness of RT information at ECR showed that RT information was missing from the cancer registry for $31.2 \%$ of cases for whom EHIF had claims for RT performed within 12 months of diagnosis. The proportion of RT information missing from ECR was $33 \%, 27 \%, 33 \%, 28$ and $38 \%$ for stages I, II, III, IV and unknown, respectively. In addition, for $6.8 \%$ of cases with reported RT, there was no date at ECR, and the timing of RT could not be assessed. The agreement for not receiving RT was $99.2 \%$ between EHIF and ECR. Among the 33 cases with discordant information, 11 cases did not have any claims at EHIF, for 5 cases, there was a claim only for RT planning, and for 17 cases, RT was performed later that 12 months since diagnosis, but there was no date at ECR to assess the timing of RT.

\section{Discussion}

In this population-based record linkage study of over 8600 women with BC, we found a significant impact of social factors such as the patients' educational level and 
Table 1 Characteristics of women with breast cancer and receipt of radiation therapy, Estonia 2007-2018

\begin{tabular}{|c|c|c|c|c|c|c|c|}
\hline \multirow[b]{3}{*}{ Variable } & \multirow[b]{3}{*}{ No. } & \multirow[b]{3}{*}{$\%$} & \multicolumn{4}{|c|}{ Receipt of radiation therapy } & \multirow[b]{3}{*}{$p$-value ${ }^{a}$} \\
\hline & & & \multicolumn{2}{|l|}{ Yes } & \multicolumn{2}{|l|}{ No } & \\
\hline & & & No. & row $\%$ & No. & row\% & \\
\hline$\overline{\text { Total }}$ & 8637 & 100 & 4310 & 49.9 & 4327 & 50.1 & \\
\hline Microscopically verified & 8387 & 97.1 & 4305 & 51.3 & 4082 & 48.7 & $<0.001$ \\
\hline \multicolumn{8}{|l|}{ Period of diagnosis } \\
\hline 2007-2009 & 1939 & 22.5 & 758 & 39.1 & 1181 & 60.9 & \multirow[t]{4}{*}{$<0.001$} \\
\hline 2010-2012 & 2144 & 24.8 & 1041 & 48.6 & 1103 & 51.5 & \\
\hline 2013-2015 & 2218 & 25.7 & 1158 & 52.2 & 1060 & 47.8 & \\
\hline 2016-2018 & 2336 & 27.1 & 1353 & 57.9 & 983 & 42.1 & \\
\hline \multicolumn{8}{|l|}{ Age at diagnosis (years) } \\
\hline$<50$ & 1523 & 17.6 & 943 & 61.9 & 580 & 38.1 & \multirow[t]{4}{*}{$<0.001$} \\
\hline $50-59$ & 1993 & 23.1 & 1297 & 65.1 & 696 & 34.9 & \\
\hline $60-69$ & 2057 & 23.8 & 1230 & 59.8 & 827 & 40.2 & \\
\hline$\geq 70$ & 3064 & 35.5 & 840 & 27.4 & 2224 & 72.6 & \\
\hline \multicolumn{8}{|l|}{ TNM stage } \\
\hline । & 2483 & 28.8 & 1642 & 66.1 & 841 & 33.9 & \multirow[t]{5}{*}{$<0.001$} \\
\hline$\|$ & 3238 & 37.5 & 1531 & 47.3 & 1707 & 52.7 & \\
\hline III & 1574 & 18.2 & 839 & 53.3 & 735 & 46.7 & \\
\hline IV & 718 & 8.3 & 82 & 11.4 & 636 & 88.6 & \\
\hline Unknown & 624 & 7.2 & 216 & 34.6 & 408 & 65.4 & \\
\hline \multicolumn{8}{|l|}{ Nationality } \\
\hline Estonian & 5490 & 63.6 & 2753 & 50.2 & 2737 & 49.9 & \multirow[t]{3}{*}{0.163} \\
\hline Other nationalities & 3112 & 36.0 & 1545 & 49.7 & 1567 & 50.4 & \\
\hline Unknown & 35 & 0.4 & 12 & 34.3 & 23 & 65.7 & \\
\hline \multicolumn{8}{|l|}{ Region of residence } \\
\hline North & 4010 & 46.4 & 1991 & 49.7 & 2019 & 50.4 & \multirow[t]{5}{*}{$<0.001$} \\
\hline West & 927 & 10.7 & 420 & 45.3 & 507 & 54.7 & \\
\hline Central & 704 & 8.2 & 347 & 49.3 & 357 & 50.7 & \\
\hline North-East & 1077 & 12.5 & 518 & 48.1 & 559 & 51.9 & \\
\hline South & 1919 & 22.2 & 1034 & 53.9 & 885 & 46.1 & \\
\hline \multicolumn{8}{|l|}{ Educational level } \\
\hline University degree & 1964 & 22.7 & 1139 & 58.0 & 825 & 42.0 & \multirow[t]{5}{*}{$<0.001$} \\
\hline Secondary plus vocational studies & 1860 & 21.5 & 1079 & 58.0 & 781 & 42.0 & \\
\hline Secondary studies & 2593 & 30.0 & 1345 & 51.8 & 1248 & 48.1 & \\
\hline Basic and primary studies & 1410 & 16.3 & 406 & 28.8 & 1004 & 71.2 & \\
\hline Unknown & 810 & 9.4 & 341 & 42.1 & 469 & 57.9 & \\
\hline \multicolumn{8}{|l|}{ Marital Status } \\
\hline Married & 3035 & 35.1 & 1818 & 59.9 & 1217 & 40.1 & \multirow[t]{4}{*}{$<0.001$} \\
\hline Divorced/widow & 4389 & 50.8 & 1898 & 43.2 & 2491 & 56.8 & \\
\hline Single & 976 & 11.3 & 488 & 50.0 & 488 & 50.0 & \\
\hline Unknown & 237 & 2.7 & 106 & 44.7 & 131 & 55.3 & \\
\hline Primary surgical treatment & & & & & & & \\
\hline Yes & 7075 & 81.9 & 4230 & 59.8 & 2845 & 40.2 & $<0.001$ \\
\hline No & 1562 & 18.1 & 80 & 5.1 & 1482 & 94.9 & \\
\hline Chemotherapy & & & & & & & \\
\hline Yes & 5518 & 63.9 & 3147 & 57.0 & 2371 & 43.0 & $<0.001$ \\
\hline No & 3119 & 36.1 & 1163 & 37.3 & 1965 & 62.7 & \\
\hline
\end{tabular}

Due to rounding, percentages may not total 100

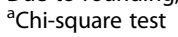


Table 2 Receipt of radiation therapy over time, Estonia 2007-2018

\begin{tabular}{|c|c|c|c|c|c|c|c|c|c|c|}
\hline & \multicolumn{8}{|c|}{ Receipt of radiation therapy } & \multirow[b]{3}{*}{ Change $^{b}$} & \multirow[b]{3}{*}{$p$-value } \\
\hline & \multicolumn{2}{|c|}{$\begin{array}{l}2007-2009 \\
N=1116^{\mathrm{a}}\end{array}$} & \multicolumn{2}{|c|}{$\begin{array}{l}2010-2012 \\
N=1185^{\mathrm{a}}\end{array}$} & \multicolumn{2}{|c|}{$\begin{array}{l}2013-2015 \\
N=1153^{\mathrm{a}}\end{array}$} & \multicolumn{2}{|c|}{$\begin{array}{l}2016-2018 \\
N=1248^{\mathrm{a}}\end{array}$} & & \\
\hline & No. & row\% & No. & row $\%$ & No. & row $\%$ & No. & row\% & & \\
\hline Total & 635 & 56.9 & 786 & 66.3 & 823 & 71.4 & 977 & 78.3 & 21.4 & $<0.001$ \\
\hline \multicolumn{11}{|l|}{ Age at diagnosis (years) } \\
\hline$<50$ & 178 & 58.0 & 222 & 67.1 & 191 & 62.8 & 263 & 77.1 & 19.1 & $<0.001$ \\
\hline $50-59$ & 264 & 61.1 & 296 & 67.7 & 327 & 76.9 & 329 & 78.7 & 17.6 & $<0.001$ \\
\hline $60-69$ & 193 & 51.2 & 268 & 64.3 & 305 & 71.9 & 385 & 78.7 & 27.5 & $<0.001$ \\
\hline \multicolumn{11}{|l|}{ TNM stage } \\
\hline । & 266 & 72.7 & 309 & 75.6 & 370 & 80.8 & 407 & 80.1 & 7.4 & 0.014 \\
\hline$\|$ & 219 & 46.1 & 314 & 57.3 & 303 & 61.3 & 390 & 73.5 & 27.4 & $<0.001$ \\
\hline III & 150 & 54.6 & 163 & 71.5 & 150 & 74.6 & 180 & 86.1 & 31.5 & $<0.001$ \\
\hline \multicolumn{11}{|l|}{ Nationality ${ }^{\mathrm{d}}$} \\
\hline Estonian & 403 & 57.2 & 493 & 68.6 & 502 & 69.6 & 608 & 78.7 & 21.5 & $<0.001$ \\
\hline Other nationalities & 230 & 56.2 & 292 & 63.1 & 320 & 74.4 & 366 & 77.5 & 21.3 & $<0.001$ \\
\hline \multicolumn{11}{|l|}{ Region of residence } \\
\hline North & 272 & 55.1 & 371 & 66.5 & 405 & 71.6 & 466 & 76.4 & 21.3 & $<0.001$ \\
\hline West & 66 & 53.7 & 82 & 65.6 & 70 & 69.3 & 92 & 75.4 & 21.7 & 0.003 \\
\hline Central & 54 & 55.1 & 58 & 66.7 & 62 & 66.0 & 92 & 79.3 & 24.2 & 0.002 \\
\hline North-East & 85 & 59.0 & 100 & 62.5 & 98 & 72.6 & 121 & 82.9 & 23.9 & $<0.001$ \\
\hline South & 158 & 61.5 & 175 & 68.6 & 188 & 73.2 & 206 & 81.1 & 19.6 & $<0.001$ \\
\hline \multicolumn{11}{|l|}{ Educational level $^{d}$} \\
\hline University degree & 157 & 59.3 & 212 & 66.5 & 251 & 72.1 & 285 & 76.0 & 16.7 & $<0.001$ \\
\hline Secondary plus vocational studies & 162 & 59.8 & 211 & 68.3 & 217 & 73.3 & 266 & 78.7 & 18.9 & $<0.001$ \\
\hline Secondary studies & 222 & 56.6 & 258 & 64.7 & 257 & 72.8 & 316 & 80.2 & 23.6 & $<0.001$ \\
\hline Basic and primary studies & 42 & 42.4 & 52 & 64.2 & 53 & 58.2 & 55 & 73.3 & 30.9 & $<0.001$ \\
\hline \multicolumn{11}{|l|}{ Marital status ${ }^{d}$} \\
\hline Married & 279 & 59.9 & 392 & 70.0 & 366 & 73.9 & 464 & 79.7 & 19.8 & $<0.001$ \\
\hline Divorced/widow & 272 & 54.1 & 289 & 63.5 & 337 & 70.7 & 352 & 77.4 & 23.3 & $<0.001$ \\
\hline Single & 67 & 55.8 & 92 & 63.0 & 92 & 64.8 & 127 & 74.3 & 18.5 & 0.011 \\
\hline
\end{tabular}

Includes women with stage I-III breast cancer, age $<70$ years who underwent primary surgery

${ }^{\mathrm{b}}$ From first to last period

${ }^{c}$ Chi-square test

dUnknown category not shown

marital status on receipt of RT. We did not find significant associations between RT utilization and nationality or place of residence. The utilization of RT increased considerably over time, particularly for age group 60-69, stage III, and women with the lowest level of education.

The main strength of the study was the identification of $\mathrm{BC}$ cases from a high-quality cancer registry, with additional data on cancer treatment and sociodemographic factors obtained from two large national databases through individual linkages. Insurance claims have not been previously used to identify cancer treatment in Estonia. The validation of the primary RT variable against data collected from medical records showed a
99.4\% agreement between these databases. The likely explanation for the minor discrepancy (two cases with missing insurance claims) is that data from medical records were collected from multidisciplinary meeting notes, which recorded treatment that was planned, but not actually performed. There were 17 cases identified from EHIF that had claims for RT planning, but no procedures. The study demonstrated the ability to use insurance claims data to define variables of cancer treatment. This is particularly important, as the additional analysis showed inadequate completeness of RT data reported to ECR and using ECR data only could lead to underestimation of the use of RT. 
Table 3 Prevalence rate ratio of radiation therapy use among women with breast cancer, Estonia 2007-2018

\begin{tabular}{|c|c|c|c|c|}
\hline & Radia & $4312)^{a}$ & Univariate PRR & Multivariate \\
\hline & No. & $\%$ & & \\
\hline Total & 2954 & 68.5 & & \\
\hline Period of diagnosis & & & & \\
\hline $2007-2009$ & 569 & 56.6 & Ref & Ref \\
\hline 2010-2012 & 727 & 66.5 & $1.18(1.10-1.26)$ & $1.18(1.10-1.26)$ \\
\hline 2013-2015 & 759 & 71.6 & $1.27(1.18-1.35)$ & $1.26(1.18-1.35)$ \\
\hline 2016-2018 & 899 & 78.0 & $1.38(1.30-1.47)$ & $1.37(1.29-1.45)$ \\
\hline Age at diagnosis (years) & & & & \\
\hline$<50$ & 802 & 66.5 & $0.94(0.89-0.99)$ & $0.96(0.91-1.01)$ \\
\hline $50-59$ & 1126 & 70.9 & Ref & Ref \\
\hline $60-69$ & 1026 & 67.6 & $0.95(0.91-1.00)$ & $0.95(0.91-1.00)$ \\
\hline TNM stage & & & & \\
\hline । & 1236 & 77.7 & Ref & Ref \\
\hline$\|$ & 1140 & 60.2 & $0.77(0.74-0.81)$ & $0.79(0.75-0.82)$ \\
\hline III & 578 & 69.9 & $0.90(0.85-0.95)$ & $0.93(0.88-0.98)$ \\
\hline Nationality & & & & \\
\hline Estonian & 1805 & 68.9 & Ref & Ref \\
\hline Other nationalities & 1149 & 67.9 & $0.98(0.94-1.03)$ & $0.98(0.93-1.02)$ \\
\hline Region of residence & & & & \\
\hline North & 1340 & 67.6 & Ref & Ref \\
\hline West & 296 & 65.8 & $0.97(0.90-1.05)$ & $0.99(0.92-1.07)$ \\
\hline Central & 249 & 68.4 & $1.01(0.94-1.09)$ & $1.01(0.94-1.09)$ \\
\hline North-East & 397 & 69.0 & $1.02(0.96-1.09)$ & $1.04(0.98-1.11)$ \\
\hline South & 672 & 71.3 & $1.05(1.00-1.11)$ & $1.04(0.99-1.10)$ \\
\hline Educational level & & & & \\
\hline University degree & 874 & 69.2 & Ref & Ref \\
\hline Secondary plus vocational studies & 846 & 70.6 & $1.02(0.97-1.07)$ & $1.02(0.97-1.08)$ \\
\hline Secondary studies & 1036 & 68.5 & $0.99(0.94-1.04)$ & $1.01(0.96-1.06)$ \\
\hline Basic and primary studies & 198 & 58.6 & $0.85(0.77-0.93)$ & $0.88(0.80-0.97)$ \\
\hline Marital status & & & & \\
\hline Married & 1395 & 71.2 & Ref & Ref \\
\hline Divorced/widowed & 1193 & 66.6 & $0.93(0.90-0.98)$ & $0.95(0.91-0.99)$ \\
\hline Single & 366 & 65.2 & $0.92(0.86-0.98)$ & $0.92(0.86-0.99)$ \\
\hline
\end{tabular}

Statistically significant results in bold

Abbreviations: PRR prevalence rate ratio, ref reference category

ancludes women with stage I-III breast cancer, age $<70$ years who underwent primary surgery and had data on sociodemographic variables

The main limitations of this study are lack of data on comorbidities, performance status and molecular profile of tumours, which may seriously affect the choice of treatment and the administration of RT. We did not have any data on patient preferences, which may play a large role. However, we limited the analysis to surgically treated patients, as a proxy for overall health status or patient compliance, to account for factors that we were not able to measure. The focus was on sociodemographic factors, so examining the utilization of RT according to mode of surgery (BCS versus mastectomy) was beyond the scope of this paper. We did not account for type of surgery in regression modelling as social determinants impact the choice of primary treatment (BCS + RT or mastectomy) prior to surgery. A sensitivity analysis using $\mathrm{BCS}+\mathrm{RT}$ as an outcome variable in early $\mathrm{BC}$ patients demonstrated similar associations for social factors, confirming the validity of our results.

During the whole study period of 2007-2018, half of the study population received RT within 12 months 
from diagnosis, which is comparable to data from the United States (51\% during 2009-2018) [40]. Overall RT utilization reached $58 \%$ for 2016-2018, which is somewhat lower than the $63 \%$ shown for England in 20132014 [41]. Stage-specific RT utilization in England was $70 \%, 65$ and $80 \%$, for stages I, II and III, respectively, compared to Estonian respective estimates of $68 \%, 59$ and $68 \%$ during 2016-2018 (data not shown). The proportion of stage IV patients receiving RT was considerably lower in Estonia (11\% in 2016-2018, data not shown) compared to both United States and England.

Lower RT utilization in Estonia is in line with inferior availability of RT equipment - in 2012, the total number of MV units per million population in Estonia was 3.0, while it was 5.1 in England [14]. Although the total number of MV units reached six in 2016 (4.6 per million population), the estimated need is nine MV units according to Estonian Cancer Control Plan for 2021-2030 [42]. The difference between actual and optimal number of radiotherapy courses was estimated to be -1216 for 2013-2017 [42]. Nevertheless, our finding that RT utilization increased over time is consistent with increasing availability of RT equipment over the study period, and also with prior studies conducted in other countries including New Zealand and Canada [27, 29]. Besides lack of equipment, another possible reason for less frequent RT use in Estonia is higher prevalence of comorbidities. A previous study showed that among early BC patients, the proportion of women with no comorbidities was the lowest in Estonia among nine European countries [8].

Overall, patients aged 70 years and over had the lowest proportion of RT use, which was more than two times lower than for younger age groups. These findings are consistent with previous studies showing association between age at diagnosis and receipt of RT [27, 28, 30]. Less frequent RT use in women aged $\geq 70$ years is in line with growing evidence over the time period under study suggesting no benefit for women in this age group in early disease [43, 44]. In multivariate analysis, RT utilization was the highest among women aged 50-59 and the difference from older and younger age groups was borderline significant. It has been reported previously that mortality from BC among patients aged 50-59 in Estonia has significantly declined since 2000 , while it did not decrease among women aged $\geq 60$ over the same time period [2]. Whereas these trends are consistent with screening activities, as women aged 50-59 have been the target age group for organized mammography screening since 2004 [20], the impact of RT in combination with other therapies can be considered as well. Women under 50 years of age were less likely to receive RT than women aged 50-59, which may be associated with higher proportion of genetically determined cancers in this age group and recommendations to use mastectomy rather than BCS and RT in cases with $\mathrm{BC}$ gene (BRCA) mutations [45]. Growing availability of immediate reconstruction may facilitate the choice of mastectomy in younger women.

In this study, no differences were observed by region of residence in multivariate analysis, even though overall receipt of RT was highest among women living in Southern Estonia and lowest among those living in Western Estonia. As living in rural areas and geographically remote areas have been shown to be one of the barriers to receipt of RT [26, 30-32], equal access to RT regardless of geographic factors in Estonia can be partly attributed to the opportunity to stay at the hospital for the duration of treatment, but also to urban life style of majority of Estonian residents. According to Statistics Estonia, approximately two-thirds of population in Estonia live in urban regions, and among people living in rural areas, those living in the suburbs of larger cities have urban lifestyles in which employment in agriculture has decreased [46].The finding of no association with place of residence is encouraging and suggests equal access to RT in Estonia regardless of geographic factors.

However, we observed significantly lower RT utilization among women with the lowest level of education, thus demonstrating an impact of social determinants on the use of RT. Educational level as an indicator of socioeconomic status has been shown to be associated with poorer health outcomes in Estonia, partly mediated by lower access to health care [1719, 47]. Factors influencing receipt of optimal cancer treatment can be divided into three main categories: structural factors, factors affecting physician recommendation and factors affecting patient's decision making [48]. Even though structural barriers such as lack of health insurance may affect timely presentation, all patients in Estonia who receive a cancer diagnosis obtain insurance coverage and consequently, access to standard treatment. Besides clinical factors, physicians' recommendations may be influenced by their perception of patient's ability to comply with treatments, while patient-related factors include socioeconomic status, access to transportation, ability to take time off from work, but also patients' attitudes towards treatments and their beliefs [48]. Our finding that higher level of education was a considerable predictor of increased RT utilization is consistent with prior studies [28, 49] and may be related to both physician- and patient-related factors. Several studies have observed that patients with higher level of education were more likely to receive BCS in comparison to other types of surgeries [25, 50-52]. Patients with lower socioeconomic status level may struggle to cope 
with healthcare systems, have misperceptions about treatment benefits and may be more likely to have difficulties in overcoming adverse effects of treatment or psycho-social problems [48].

RT use was significantly associated with marital status, as divorced/widowed and single women received RT less often than married women. These findings are consistent with previous reports elsewhere [26, 53]. Furthermore, previous studies have shown marital status to be a predictor of cancer survival [54-58]. Longer survival of married individuals can be attributed to increased social support and improved economic status [59]. Studies have shown that unmarried women are more concerned about insufficient care after their treatment, and seeking help and transportation in comparison to married women and are thus more prone to refuse intense treatments and decline therapies such as axillary dissection and RT [60]. Such concerns can also have an impact on physician recommendations and physicians may be less likely to offer intense treatments to unmarried older women [57]. It might be beneficial for healthcare providers to identify unmarried women and provide comprehensive case managements to reduce health disparities. Studies have shown implementing nurse case management has improved receipt of RT among older BC patients, particularly those with poor social support [61].

\section{Conclusions}

In conclusion, this study demonstrated the ability to use administrative databases as an additional source for identifying individual cancer treatment data if such data are not complete at a cancer registry. The study showed considerable increase in the use of RT in Estonia over the study period, which is in line with increases in available equipment. The lack of geographic variations suggests equal access to therapy for patients living in remote regions. However, unmarried women and those with lower educational level received less RT compared to their counterparts, revealing the impact of social factors on the use of health services. Further studies are needed to identify the exact mechanisms behind these findings, but some of the likely reasons are misperceptions about treatment benefits, loss of social support and economical disadvantages. The results have important implications for policymaking and evidence-based decisions. To minimise disparities in BC outcomes and avoid inequitable delivery of RT in Estonia, the healthcare and social system need a stronger focus on patient-centred care, offering patients psychosocial support, helping them cope with the disease and treatment effects and overcome any barriers to treatment.

\begin{abstract}
Abbreviations
BC: Breast cancer; RT: RTRT; BCS: Breast conserving surgery; ECR: Estonian Cancer Registry; EHIF: Estonian Health Insurance Funds; ICD-O-3: $3^{\text {rd }}$ Edition of International Classification of Disease for Oncology; ICD-10: International Statistical Classification of Diseases and Health Problems $10^{\text {th }}$ Revision; PRR: Prevalence rate ratio; Cl: Confidence intervals; MV: Megavoltage; IMRT: Intensity modulated radiation therapy; IGRT: Image-guided radiation therapy
\end{abstract}

\section{Acknowledgements \\ The authors thank Dr Margit Mägi and Mrs Pille Härmaorg from the Estonian} Cancer Registry for providing cancer registry data.

\section{Authors' contributions}

FSF and KI designed the study, Kl obtained the data, FSF and KI performed data analysis, FSF wrote the first draft, KP and KI revised the manuscript critically, all authors read and approved the final manuscript.

Funding

This work was supported by Estonian Research Council (grant no PRG722).

\section{Availability of data and materials}

The datasets generated and analysed during this study are available from the corresponding author on reasonable request.

\section{Declarations}

Ethics approval and consent to participate

The study protocol was approved by Tallinn Medical Research Ethics Committee (Decision no 2652, March 12, 2019). Consent to participate not applicable.

Consent for publication

Not applicable.

\section{Competing interests}

The authors declare that they have no competing interests.

\section{Author details}

${ }^{1}$ School of Information Technologies, Department of Health Technologies, Tallinn University of Technology, Digital Health MSc Programme, Tallinn, Estonia. ${ }^{2}$ Department of Epidemiology and Biostatistics, National Institute for Health Development, Hiiu 42, 11619 Tallinn, Estonia.

Received: 31 March 2021 Accepted: 11 June 2021

Published online: 30 June 2021

\section{References}

1. Arnold M, Karim-Kos HE, Coebergh JW, Byrnes G, Antilla A, Ferlay J, et al. Recent trends in incidence of five common cancers in 26 European countries since 1988: Analysis of the European Cancer Observatory. Eur J Cancer. 2015;51(9):1164-87.

2. Baburin A, Aareleid T, Rahu M, Reedik L, Innos K. Recent changes in breast cancer incidence and mortality in Estonia: Transition to the west. Acta Oncol. 2016;55(6):728-33.

3. Allemani C, Matsuda T, Di Carlo V, Harewood R, Matz M, Nikšić M, et al. Global surveillance of trends in cancer survival 2000-14 (CONCORD-3): analysis of individual records for 37513025 patients diagnosed with one of 18 cancers from 322 population-based registries in 71 countries. Lancet. 2018;391(10125):1023-75.

4. Baburin A, Aareleid T, Padrik P, Valvere V, Innos K. Time trends in population-based breast cancer survival in Estonia: Analysis by age and stage. Acta Oncol. 2014;53(2):226-34.

5. Mägi M, Härmaorg P, Innos K. Cancer in Estonia 2017. Tallinn: National Institute for Health Development; 2020. Available from: https://intra.tai.ee// images/prints/documents/159129026779_Cancer_in_Estonia_2017.pdf [cited 21 Mar 2021].

6. Danckert B, Ferlay J, Engholm G, Hansen HL, Johannesen TB, Khan S, et al. NORDCAN: Cancer Incidence, Mortality, Prevalence and Survival in the 
Nordic Countries, Version 8.2 (26.03.2019). Association of the Nordic Cancer Registries. Danish Cancer Society. Available from http://www.ancr.nu [cited $26 \mathrm{Mar} 2021]$.

7. Office for National Statistics. Cancer survival in England: adult, stage at diagnosis and childhood - patients followed up to 2018. Available from: https://www.ons.gov.uk/peoplepopulationandcommunity/healthandsocialca re/conditionsanddiseases/datasets/cancersurvivalratescancersurvivalinengla ndadultsdiagnosed [cited 14 May 2021].

8. Minicozzi P, Van Eycken L, Molinie F, Innos K, Guevara M, Marcos-Gragera R, et al. Comorbidities, age and period of diagnosis influence treatment and outcomes in early breast cancer. Int J Cancer. 2019;144(9):2118-27.

9. Cardoso F, Kyriakides S, Ohno S, Penault-Llorca F, Poortmans P, Rubio IT, et al. Early breast cancer: ESMO Clinical Practice Guidelines for diagnosis, treatment and follow-up. Ann Oncol. 2019;30(8):1194-220.

10. Veronesi U, Alberto L, Vecchio M, Del, Greco M, Galimberti V, Mirella M, et al. Radiotherapy after breast-preserving surgery in women with localized cancer of the breast. N Engl J Med. 1993;328(22):1587-91.

11. Fisher B, Anderson S, Bryant J, Margolese RG, Deutsch M, Fisher ER, et al. Twenty-Year Follow-Up of a Randomized Trial Comparing Total for the Treatment of Invasive Breast Cancer. N Engl J Med. 2002;347(16):1233-41.

12. Darby S, McGale P, Correa C, Taylor C, Arriagada R, Clarke M, et al. Effect of radiotherapy after breast-conserving surgery on 10-year recurrence and $15-$ year breast cancer death: Meta-analysis of individual patient data for 10801 women in 17 randomised trials. Lancet. 2011;378(9804):1707-16.

13. Cardoso F, Senkus E, Costa A, Papadopoulos E, Aapro M, André F, et al. 4th ESO-ESMO international consensus guidelines for advanced breast cancer (ABC 4). Ann Oncol. 2018;29(8):1634-57.

14. Grau C, Defourny N, Malicki J, Dunscombe P, Borras JM, Coffey M, et al. Radiotherapy equipment and departments in the European countries: Final results from the ESTRO-HERO survey. Radiother Oncol. 2014;112(2):155-64.

15. Sant M, Meneghini E, Bastos J, Rossi PG, Guevara M, Innos K, et al. Endocrine treatment and incidence of relapse in women with oestrogen receptorpositive breast cancer in Europe: a population-based study. Breast Cancer Res Treat. 2020;183(2):439-50.

16. Estonian Health Insurance Fund. Available from: https://www.haigekassa.ee/ en [cited 6 Jan 2021].

17. Ezendam NPM, Stirbu I, Leinsalu M, Lundberg O, Kalediene R, Wojtyniak B, et al. Educational inequalities in cancer mortality differ greatly between countries around the Baltic Sea. Eur J Cancer. 2008;44(3):454-64.

18. Gadeyne S, Menvielle G, Kulhanova I, Bopp M, Deboosere P, Eikemo TA, et al. The turn of the gradient? Educational differences in breast cancer mortality in 18 European populations during the 2000s. Int J Cancer. 2017; 141(1):33-44.

19. Leinsalu $M$, Vågerö $D$, Kunst $A E$. Estonia 1989-2000: Enormous increase in mortality differences by education. Int J Epidemiol. 2003;32(6):1081-7.

20. Innos K, Mägi M, Tekkel M, Aareleid T. Place of residence predicts breast cancer stage at diagnosis in Estonia. Eur J Public Health. 2011;21(3):376-80

21. Banerjee M, George J, Yee C, Hryniuk W, Schwartz K. Disentangling the effects of race on breast cancer treatment. Cancer. 2007;110(10):2169-77.

22. Lin Y, Wimberly MC, Da Rosa P, Hoover J, Athas WF. Geographic access to radiation therapy facilities and disparities of early-stage breast cancer treatment. Geospat Health. 2018;13(1):93-101.

23. Lautner $\mathrm{M}$, Lin $\mathrm{H}$, Shen $\mathrm{Y}$, Parker $\mathrm{C}$, Kuerer $\mathrm{H}$, Shaitelman $\mathrm{S}$, et al. Disparities in the use of breast-conserving therapy among patients with early-stage breast cancer. JAMA Surg. 2015:150(8):778-86.

24. Voti L, Richardson LC, Reis IM, Fleming LE, MacKinnon J, Coebergh JWW. Treatment of local breast carcinoma in Florida: The role of the distance to radiation therapy facilities. Cancer. 2006;106(1):201-7.

25. Liu Y, Zhang J, Huang R, Feng W-L, Kong Y-N, Xu F, et al. Influence of occupation and education level on breast cancer stage at diagnosis, and treatment options in China: A nationwide, multicenter 10-year epidemiological study. Medicine. 2017;96(15):e6641.

26. Wheeler SB, Kuo TM, Durham D, Frizzelle B, Reeder-Hayes K, Meyer AM. Effects of distance to care and rural or urban residence on receipt of radiation therapy among North Carolina Medicare enrollees with breast cancer. N C Med J. 2014;75(4):239-46.

27. Seneviratne S, Campbell I, Scott N, Lawrenson R. A cohort study of ethnic differences in use of adjuvant chemotherapy and radiation therapy for breast cancer in New Zealand. BMC Health Serv Res. 2017;17(1):1-10.

28. Parekh A, Fu W, Hu C, Shen CJ, Alcorn S, Rao AD, et al. Impact of race, ethnicity, and socioeconomic factors on receipt of radiation after breast conservation surgery: analysis of the national cancer database. Breast Cancer Res Treat. 2018;172(1):201-8.

29. Liu E, Santibáñez P, Puterman ML, Weber L, Ma X, Sauré A, et al. A Quantitative Analysis of the Relationship between Radiation Therapy Use and Travel Time. Int J Radiat Oncol Biol Phys. 2015;93(3):710-8.

30. Baldwin LM, Patel S, Andrilla CHA, Rosenblatt RA, Doescher MP. Receipt of recommended radiation therapy among rural and urban cancer patients. Cancer. 2012;118(20):5100-9.

31. Athas WF, Adams-Cameron M, Hunt WC, Amir-Fazli A, Key CR. Travel distance to radiation therapy and receipt of radiotherapy following breastconserving surgery. J Natl Cancer Inst. 2000;92(3):269-71.

32. Dragun AE, Huang B, Tucker TC, Spanos WJ. Disparities in the application of adjuvant radiotherapy after breast-conserving surgery for early stage breast cancer. Cancer. 2011;117(12):2590-8.

33. Allemani C, Storm H, Voogd AC, Holli K, Izarzugaza II, Torrella-Ramos A, et al. Variation in "standard care" for breast cancer across Europe: A EUROCARE-3 high resolution study. Eur J Cancer. 2010;46(9):1528-36.

34. Hiatt RA, Breen N. The Social Determinants of Cancer. A Challenge for Transdisciplinary Science. Am J Prev Med. 2008:35(2S):141-50.

35. Ojamaa K, Veerus P, Baburin A, Everaus $H$, Innos K. Increasing incidence and survival of corpus uteri cancer in Estonia over the past two decades. Cancer Epidemiol. 2019;62:101566.

36. Mallin K, Palis BE, Watroba N, Stewart AK, Walczak D, Singer J, et al. Completeness of American cancer registry treatment data: Implications for quality of care research. J Am Coll Surg. 2013;216(3):428-37.

37. Malin JL, Kahn KL, Adams J, Kwan L, Laouri M, Ganz PA. Validity of cancer registry data for measuring the quality of breast cancer care. J Natl Cancer Inst. 2002;94(11):835-44.

38. StataCorp. Stata Statistical Software Release 16. College Station. TX: StataCorp LLC; 2019

39. Cummings P. Methods for estimating adjusted risk ratios. Stata J. 2009;9(2): $175-96$.

40. NCDB Public Benchmark Reports. Available from: http://oliver.facs.org/ BMPub/index.cfm [cited 20 Mar 2021].

41. Cancer Research UK. Available from: https://www.cancerresearchuk.org/hea Ith-professional/cancer-statistics/statistics-by-cancer-type/breast-cancer/dia gnosis-and-treatment\#heading-Two [cited 20 Mar 2021].

42. Estonian Cancer Control Plan 2021-2030 [Vähitõrje tegevuskava 2021-2030]. Tallinn: Sotsiaalministeerium, Tervise Arengu Instituut; 2021. Available from: https://www.sm.ee/sites/default/files/content-editors/Tervishoid/Nahiravi/va hitorje_tegevuskava_2021-2030.pdf.

43. Smith BD, Gross CP, Smith GL, Galusha DH, Bekelman JE, Haffty BG. Effectiveness of radiation therapy for older women with early breast cancer. J Natl Cancer Inst. 2006;98(10):681-90.

44. Hughes KS, Schnaper LA, Bellon JR, Cirrincione CT, Berry DA, McCormick B, et al. Lumpectomy plus tamoxifen with or without irradiation in women age 70 years or older with early breast cancer: Long-term follow-up of CALGB 9343. J Clin Oncol. 2013;31(19):2382-7.

45. Metcalfe K, Lynch HT, Ghadirian P, Tung N, Olivotto I, Warner E, et al. Contralateral breast cancer in BRCA1 and BRCA2 mutation carriers. J Clin Oncol. 2004;22(12):2328-35.

46. Estonian HDevelopmentR. 2019/2020. Available from: https://inimareng.ee/ en/changes-in-land-use-distortion-of-the-meaning-of-urban-and-rural.html [cited 15 Mar 2021].

47. Rydland HT, Fjær EL, Eikemo TA, Huijts T, Bambra C, Wendt C, et al. Educational inequalities in mortality amenable to healthcare. A comparison of European healthcare systems. PLoS One. 2020;15(7):1-17.

48. Shavers VL, Brown ML. Racial and ethnic disparities in the receipt of cancer treatment. J Natl Cancer Inst. 2002:94(5):334-57.

49. Ballard-Barbash R, Potosky AL, Harlan LC, Nayfield SG, Kessler LG. Factors associated with surgical and radiation therapy for early stage breast cancer in older women. J Natl Cancer Inst. 1996:88(11):716-26.

50. Aarts MJ, Hamelinck VC, Bastiaannet E, Coebergh JWW, Liefers GJ, Voogd $A C$, et al. Small but significant socioeconomic inequalities in axillary staging and treatment of breast cancer in the Netherlands. Br J Cancer. 2012;107(1): 12-7.

51. Michalski TA, Nattinger AB. The influence of black race and socioeconomic status on the use of breast-conserving surgery for Medicare beneficiaries. Cancer. 1997;79(2):314-9.

52. Smith GL, Xu Y, Shih YCT, Giordano SH, Smith BD, Hunt KK, et al. BreastConserving Surgery in Older Patients with Invasive Breast Cancer: Current 
Patterns of Treatment Across the United States. J Am Coll Surg. 2009;209(4): 425-33.

53. Hershman DL, Buono D, McBride RB, Tsai WY, Joseph KA, Grann VR, et al. Surgeon characteristics and receipt of adjuvant radiotherapy in women with breast cancer. J Natl Cancer Inst. 2008;100(3):199-206.

54. Kravdal $\varnothing$. Social inequalities in cancer survival. Popul Stud (NY). 2000;54(1): $1-18$.

55. Meng L, Maskarinec G, Wilkens L. Ethnic differences and factors related to breast cancer survival in Hawaii. Int J Epidemiol. 1997;26(6):1151-8.

56. Polednak AP. Survival of breast cancer patients in Connecticut in relation to socioeconomic and health care access indicators. J Urban Heal. 2002;79(2): $211-8$.

57. Osborne C, Ostir GV, Du X, Peek MK. The influence of marital status on the stage at diagnosis, treatment, and survival of older women with breast cancer. Breast Cancer Res Treat. 2005:93:41-7.

58. Parikh DA, Chudasama R, Agarwal A, Rand A, Qureshi MM, Ngo T, et al. Race/Ethnicity, Primary Language, and Income Are Not Demographic Drivers of Mortality in Breast Cancer Patients at a Diverse Safety Net Academic Medical Center. Int J Breast Cancer. 2015;2015:1-6.

59. Rendall MS, Weden MM, Favreault MM, Waldron $\mathrm{H}$. The Protective Effect of Marriage for Survival: A Review and Update. Demography. 2011;48(2):481506.

60. Silliman R, Troyan SL, Guadagnoli E, Ph D, Kaplan SH, Ph D, et al. The Impact of Age, Marital Status, and Physician- Patient Interactions on the Care of Older Women with Breast Carcinoma. Cancer. 1997;80(7):1326-34.

61. Goodwin JS, Satish S, Anderson ET, Nattinger AB, Freeman JL. Effect of nurse case management on the treatment of older women with breast cancer. J Am Geriatr Soc. 2003;51(9):1252-9.

\section{Publisher's Note}

Springer Nature remains neutral with regard to jurisdictional claims in published maps and institutional affiliations.

Ready to submit your research? Choose BMC and benefit from:

- fast, convenient online submission

- thorough peer review by experienced researchers in your field

- rapid publication on acceptance

- support for research data, including large and complex data types

- gold Open Access which fosters wider collaboration and increased citations

- maximum visibility for your research: over $100 \mathrm{M}$ website views per year

At $\mathrm{BMC}$, research is always in progress.

Learn more biomedcentral.com/submissions 